\title{
Churg-Strauss vasculitis presenting with severe visual loss due to bilateral sequential optic neuropathy
}

\author{
J F Acheson, O C Cockerell, C R Bentley, M D Sanders
}

\begin{abstract}
A 44-year-old man with severe visual loss due to an acute bilateral sequential optic neuropathy is described, where the associated pulmonary disease and peripheral eosinophilia led to a diagnosis of Churg-Strauss syndrome (allergic angiitis). The mechanism of the optic neuropathy was most probably acute ischaemia of the anterior optic nerve due to direct involvement of the short posterior ciliary arteries by inflammatory disease of the vessel wall.

(Brf Ophthalmol 1993; 77: 118-119)
\end{abstract}

In 1951 Churg and Strauss first reported 13 cases of adult onset asthma followed by systemic vasculitis associated with peripheral eosinophilia. ${ }^{1}$ Histologically there was evidence of necrotising arteritis, eosinophilic infiltration of tissues, and extravascular granulomas and the disease became known as allergic granulomatosis, allergic angiitis, or Churg-Strauss syndrome. ${ }^{2-4}$ Ophthalmic manifestations include eosinophilic granulomas in the eyelids and conjunctiva, ${ }^{56}$ and less commonly scleritis, episcleritis, and uveitis. $^{27}$ Mononeuritis multiplex may cause extraocular muscle palsies, ${ }^{8}$ and retinal ischaemic infiltrates and branch arterial occlusions have also been described..$^{90}$ To our knowledge, there is only one report of ischaemic optic neuropathy ${ }^{8}$ and we believe this to be the first report of Churg-Strauss syndrome presenting as an acute bilateral sequential optic neuropathy.

\section{Case report}

A 44-year-old man was referred to the Medical Eye Unit at St Thomas' Hospital in November 1991 because of severe bilateral visual loss. In August 1991, during an attack of asthma, he noted a rapid onset of painless progressive fading of vision in his left eye over the course of a few hours. An ophthalmologist found a swollen optic disc with a single flame haemorrhage at the disc margin and a diagnosis of optic neuritis was made. There was no abnormality in his right eye.

He remained stable until early November 1991 when he became febrile with further dyspnoea. He then noted complete loss of vision in the right eye over 3 hours. There was no pain on ocular movements. The disc in his right eye was found to be swollen. No members of his family had any eye disease. His medical history consisted of late onset asthma diagnosed 5 years earlier when he had developed episodic wheezing, cough, and dyspnoea requiring multiple hospital admissions. His respiratory symptoms were partially controlled at the time of visual loss with oral prednisolone $40 \mathrm{mg}$ daily and aerosol bronchodilators.

On examination his right visual acuity was no perception of light and the left eye saw counting fingers. The eye movements, anterior segments, and intraocular pressure were normal. There was no afferent pupillary light reaction on the right and a reduced response on the left. The left eye had no colour perception and Goldmann perimetry showed superior and inferior arcuate defects with peripheral depression leaving a residual 10 degree field. Funduscopy showed pale optic discs and retinal arterial attenuation with residual axonal swelling on the right (Figs $1 \mathrm{~A}$ and 1B). Fluorescein angiography. showed late hyperfluorescence from the right disc but no other specific abnormality.

There was a low grade pyrexia of $38^{\circ} \mathrm{C}$ with mild basal inspiratory and expiratory crackles on chest auscultation. The remaining physical examination was normal. The total white cell count was $7 \cdot 2 \times 10^{\%} / 1$ with a $22 \%$ eosinophilia of 1.6 (normal $0.04-0 \cdot 4$ ). The $\mathrm{C}$-reactive protein was $40 \mathrm{mg} / \mathrm{l}$ and the erythrocyte sedimentation rate $74 \mathrm{~mm}$ in the first hour. A chest $x$ ray showed predominantly peripheral shadowing consistent with eosinophilic infiltrate or pulmonary haemorrhage secondary to vasculitis (Fig 2). Balanced and T2 weighted axial magnetic resonance images of the head and $\mathrm{T} 1$ weighted images of the orbits showed no abnormality. The urea and electrolyes, liver function, and serum lipids were normal. Urine microscopy showed no cells or casts and culture of a mid-stream urine sample was negative. The VDRL, antinuclear factor, and anti-neutrophil cytoplasmic antibody tests were also negative. The activated partial thromboplastin time, prothrombin time, and platelet count were normal. Tests for the lupus anticoagulant and anticardiolipin antibodies and circulating immune complexes were negative and serum complement levels were normal. An infectious diseases screen for atypical respiratory viruses, Mycoplasma, Coxiella, Aspergillus, Brucella, Toxoplasma, Mycobacterium, and helminthic diseases was negative. 


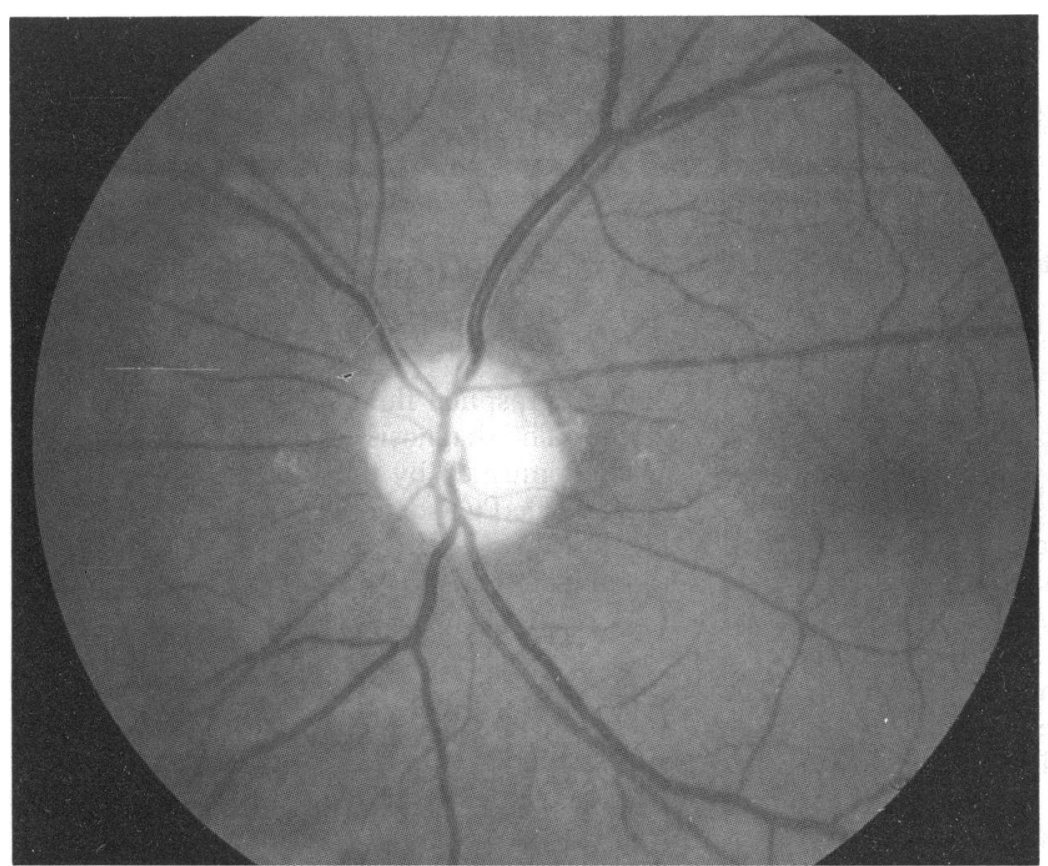

Fig $1 A$

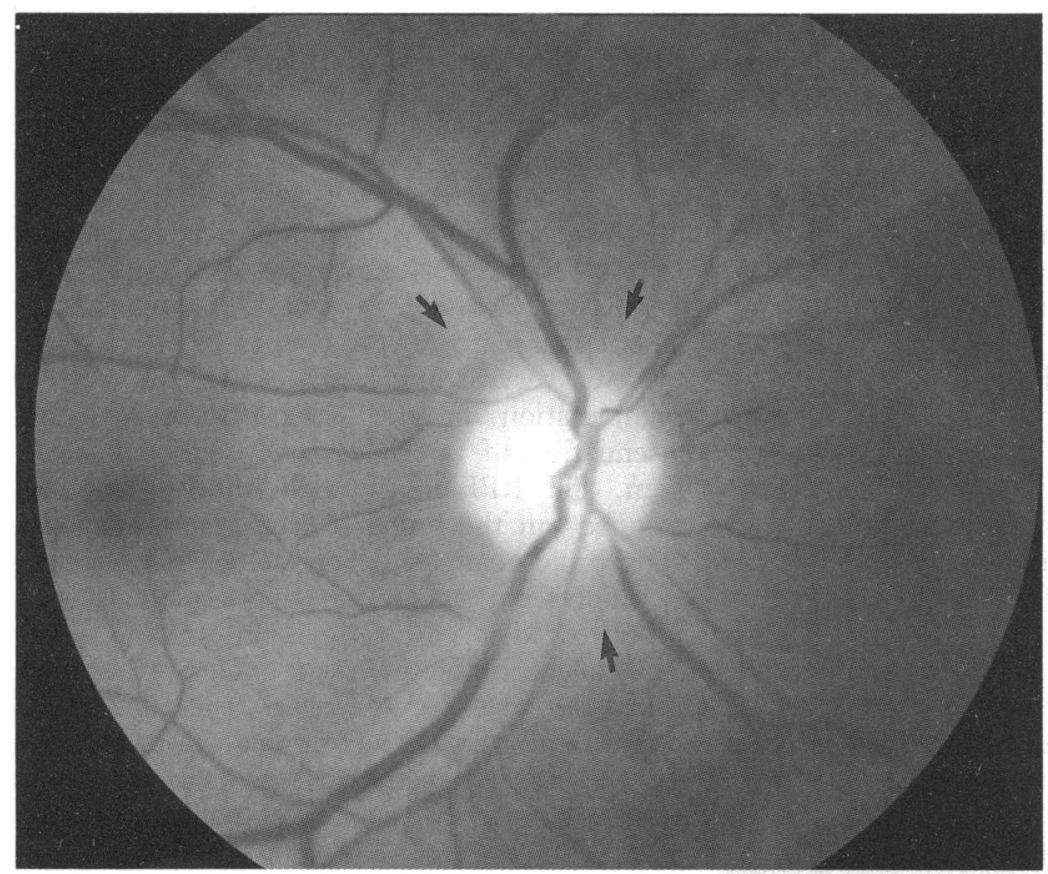

Fig $1 B$

Figure 1 (A) Fundus photograph of left eye taken 4 months after acute visual loss showing optic atrophy and retinal arteriolar attenuation. $(B)$ Fundus photograph of right eye taken 4 weeks after acute visual loss showing disc pallor with residual axonal swelling (arrows) and retinal arteriolar attenuation.

A diagnosis of Churg-Strauss syndrome was made and he was treated with pulsed intravenous cyclophosphamide $750 \mathrm{mg}$ per week for 4 weeks following which he became afebrile and the peripheral eosinophilia dropped to $12 \%$. His respiratory symptoms improved but there was no visual recovery.

\section{Comment}

With a history of asthma, more than $10 \%$ peripheral eosinophilia, radiographic demonstration of pulmonary infiltrates, and a neuropathy our case fulfils the necessary four out of six modern criteria for the diagnosis of Churg-

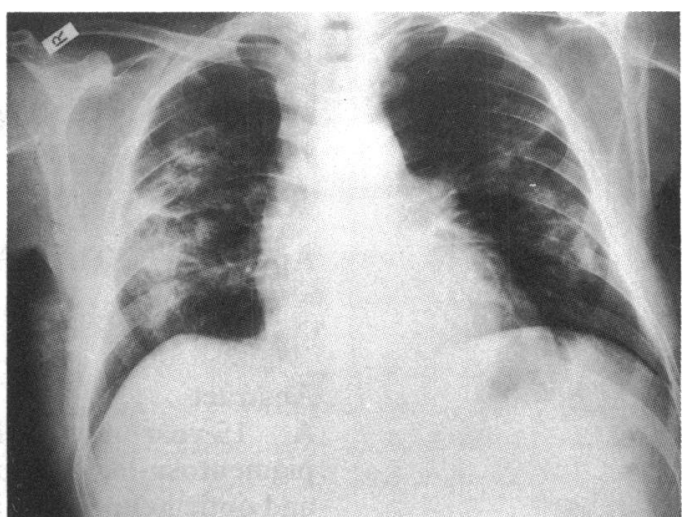

Figure 2 Posterior-anterior chest radiograph showing predominantly peripheral shadowing consistent with eosinophilic infiltrate or pulmonary haemorrhage due to vasculitis.

Strauss syndrome." These factors were considered so strong that an open lung biopsy seeking to demonstrate a blood vessel with extravascular eosinophils was not performed, so as to avoid its attendant morbidity. The visual loss with disc swelling followed by atrophy could have been due to an optic disc or retrolaminar granuloma producing neuronal damage. In this instance one would have expected a more insidious onset of symptoms, pain on ocular movements, some response to treatment with systemic steroids, and an abnormal optic nerve on magnetic resonance imaging. ${ }^{12}$ Demyelination and Leber's hereditary optic neuropathy was similarly excluded on clinical grounds. The rapid onset of painless visual loss together with the observation of peripapillary haemorrhage in the left eye at presentation strongly suggests anterior ischaemic optic neuropathy resulting in nerve head infarction and axonal degeneration. This was most probably due to direct inflammatory infiltration and fibrinoid necrosis in the walls of the short posterior ciliary arteries as part of the systemic vasculitis.

The authors thank Mr David Watson for referring this patient, $\mathrm{Mr}$ Richard Dewhirst for photographic assistance, and Miss Hazel Hollands for secretarial help.

1 Churg J, Strauss L. Allergic granulomatosis, allergic angiitis, and peri-arteritis nodosa. Am 7 Path 1959; 27: 277-300.

2 Chumbley LC, Harrison EG, De Remee RA. Allergic granulomatosis and angitis (Churg-Strauss syndrome): report and analysis of 30 cases. Mayo Clin Proc 1977; 52: 477-84.

3 Rackemanne FM, Green JE. Periarteritis nodosa and asthma. Trans Ass Am Physicians 1939; 54: 112-8.

4 Miller NR. Vasculitis. In: Walsh and Hoyt's clinical neuroophthalmology, 4th Ed. Baltimore: Williams and Wilkins, 1991: Volume 4, Chapter 60, 2598-601.

5 Shields CL, Shields JA, Rozanski TI. Conjunctival involvement in Churg-Strauss syndrome. Am $\mathcal{F}$ Ophthalmol 1986; 102: 601-5.

6 Nissim F, von der Valde J, Czernobilisky B. A limited form of Churg-Strauss syndrome. Acta Pathol Lab Med 1982; 106: 305-7.

7 Cury D, Breakley AS, Payne BF. Allergic granulomatous angiitis associated with posterior uveitis and papilloedema. angiitis associated with posterior

8 Weinstein JM, Chui H, Lane S, Corbett J, Towfighi J. ChurgStrauss syndrome (allergic granulomatous angiitis): neuroophthalmic manifestations. Arch Ophthalmol 1983; 101: $1217-1220$

9 Dagi LR, Currie J. Branch retinal artery occlusion in ChurgStrauss syndrome. F Clin Neuro Ophthalmol 1985; 5: 22937.

10 Sanders MD. Retinal arteritis, retinal vasculitis and autoimmune retinal vasculitis. Eye 1987; 1: 441-65.

11 Masi AT, Hunder GG, Lie JT, Michel BA, Bloch DA, Arend WP, et al. The American College of Rheumatology criteria for the classification of Churg-Straus syndrome (allergic granulomatous angiitis). Arthritis Rheum 1990; 33: 1094 1100 .

12 Graham EM, Ellis CJK, Sanders MD, McDonald WI. Optic neuropathy in sarcoidosis. I Neurol Neurosurg Psychiatry 1986; 49: 756-63. 